*Advogado. Possui graduação em Direito pelo Centro Universitário de Maringá - Unicesumar. E-mail para contato: lucasmonquero95@ gmail.com

** Professor Permanente do Programa de Mestrado em Ciências Jurídicas pelo Centro Universitário de Maringá Unicesumar. Possui graduação em Direito pela Universidade Estadual de Maringá (1996), mestrando em Direito das Relações Sociais pela Pontifícia Universidade Católica de São Paulo (1998) e doutorado em Direito das Relações Sociais pela Pontifícia Universidade Católica de São Paulo (2000), Pós-doutorado em Direito Educacional pela Pontifícia Universidade Católica de São Paulo (2001). Atualmente é professor permanente do Programa de Mestrado em Direito do Centro Universitário de Maringá, integrando a linha de pesquisa "A Tutela Constitucional e Privada dos Direitos da Personalidade nas Relações Privadas". Possui atuação profissional na área da advocacia e consultoria em Direito Educacional.

\footnotetext{
***Advogada com atuação profissional na área da advocacia e consultoria em Direito Educacional; mestre em Ciências Jurídicas pelo Centro Universitário de Maringá Unicesumar; pós-graduada em Docência do Ensino Superior pelo Centro Universitário de Maringá - Unicesumar; pósgraduada em Direito Processual Civil pelo Centro Universitário Internacional - Uninter; pósgraduada em Direito Aplicado pela Escola de Magistratura do Paraná; docente no curso de graduação em Direito na Unicesumar; docente formadora convidada do EAD na Unicesumar; graduada em Direito pela Pontifícia Universidade Católica do Paraná - PUC/PR. E-mail para contato: fabriziael@hotmail.com
}

\section{O ENSINO SUPERIOR À DISTÂNCIA E SUA RELAÇÃO COM O DIREITO TRIBUTÁRIO}

\author{
Lucas Vinicius Monquero* \\ Ivan Dias da Motta** \\ Fabrizia Angelica Bonatto Lonchiati***
}

Como citar: MONQUERO, Lucas Vinicius; MOTTA, Ivan Dias; LONCHIATI, Fabrizia Angelica Bonatto. O ENSINO SUPERIOR À DISTÂNCIAE SUA RELAÇÃO COM O DIREITO TRIBUTÁRIO. Revista do Instituto de Direito Constitucional e Cidadania - IDCC, Londrina, v. 4, n. 1, p 24-40, ago, 2019. ISSN: 2596-0075.

https://doi.org/10.48159/revistadoidcc.v4n1.monquero.motta.lonchiati

Resumo: O ensino superior à distância é uma das modalidades de prestação de serviço na esfera da educação, sendo que ao ocorrer este fornecimento é gerado ao Município ou ao Distrito Federal o direito a cobrança de um tributo denominado de Imposto Sobre Serviço de Qualquer Natureza (ISSQN). O conhecimento a respeito da incidência deste imposto decorrente da prestação do serviço educacional referido é o objetivo geral deste artigo, motivo pelo qual houve análise do Capítulo I, do Título VI da Constituição Federal denominado "do sistema tributário nacional", bem como foram estudados os Princípios Tributários, leis específicas pertinentes ao ensino superior à distância e ao ISSQN, além de consultados livros de doutrinadores na área tributária e igualmente uma autora na esfera do Ensino à Distância (EaD). Contudo o ser-humano possui a virtude de pensar e isto as vezes o leva a ter ideias contrárias aos demais, o que também se reflete ao entendimento quanto a aplicação das normas que regram a relação jurídica em questão, razão pela qual o presente escrito também investigou o que Superior Tribunal de Justiça e o Tribunal de Justiça do Paraná entendem sobre o objetivo geral deste artigo.

Palavras-chave: Ensino Superior à Distância. Imposto sobre Serviço de Qualquer Natureza. Mapeamento Jurisprudencial. 


\begin{abstract}
La enseñanza superior a distancia es una de las modalidades de prestación de servicio en la esfera de la educación, siendo que al ocurrir este hecho es generado a la Municipalidad o al Distrito Federal el derecho a colección de un tributo denominado de Impuesto sobre el Servicio de cualquier naturaleza (ISSQN). El conocimiento acerca de la incidencia de este impuesto derivado de la prestación del servicio educativo referido es el caput de este artículo, motivo por el cual hubo análisis del Capítulo I, del Título VI de la Constitución Federal denominado "del sistema tributario nacional", así como se estudiaron los siguientes: Principios Tributarios, leyes específicas pertinentes a la enseñanza superior a distancia y al ISSQN, además de libros de eruditos en el área tributaria y también una autora en la Enseñanza a Distancia (EaD). Sin embargo el ser humano tiene la virtud de pensar y esto a veces lo lleva a tener ideas contrarias a los demás, lo que también se refleja en el entendimiento en cuanto a la aplicación de las normas que rige la relación jurídica en cuestión, por lo que el presente artículo también investigó lo que el Tribunal Superior de Justicia y el Tribunal de Justicia de Paraná entienden sobre el objetivo general de este trabajo.
\end{abstract}

Keywords: Enseñanza Superior a Distancia. Impuesto sobre el Servicio de cualquier naturaleza. Mapeo Jurisprudencial. 


\section{INTRODUÇÃO}

No cenário atual é de se perceber a relevância de se ter conhecimentos básicos a respeito da tributação do país em que se vive, motivo pelo qual o presente artigo, por meio de pesquisa legislativa e bibliográfica ensina noções básicas sobre o que é e o que compreende o Direito Tributário, como por exemplo a relação existente entre o fisco e contribuinte.

Para tanto, o presente trabalho foi divido em três capítulos, sendo que o primeiro versou sobre o conceito de tributo e os princípios que regem o direito tributário.

No segundo capítulo buscou adentrar ao estudo de um tributo em específico, o imposto, e dentre os diversos tipos deste, examinou-se um em específico, que é o Imposto Sobre Serviço de Qualquer Natureza (ISSQN), observando suas peculiaridades, como a situação jurídica que permite o Ente Estatal cobrar o tributo do contribuinte e qual o responsável tributário pelo recolhimento desta espécie tributária, com o escopo de permitir ao leitor entender sobre a problemática deste artigo, que é onde deve incidir o ISSQN no caso da prestação do Serviço Educacional Superior à Distância.

Por fim, pensando-se na utilidade prática do presente escrito, no terceiro capítulo efetuou-se um mapeamento jurisprudencial para se compreender como o Egrégio Poder Judiciário vêm tratando sobre o assunto, ou seja, interpretando as normas que regulam o Serviço Educacional Superior à Distância.

\section{NOÇÕES BÁSICAS SOBRE O DIREITO TRIBUTÁRIO}

\subsection{O DIREITO TRIBUTÁRIO}

Iniciando-se os trabalhos, é de se apontar que no sentido de buscar a melhor compreensão do leitor, far-se-á algumas ponderações introdutórias em cada capítulo do presente escrito, eis que entendendo o básico do assunto a compreensão do que é mais complexo resta facilitada.

Sendo assim, no presente tópico começa-se a desenvolver algumas noções básicas alusivas ao Direito Tributário, como bem expõe Vinícius Casalino (2012, p. 28), pertinente a organização e sobrevivência dos Estados Soberanos, em razão deles a partir de suas Constituições puxarem para si algumas obrigações, como por exemplo de fornecer à população serviços relacionados a saúde e, em razão dessas obrigações, há a criação de um enorme encargo financeiro.

Assim, para atender essa necessidade, o Estado Soberano tem que possuir métodos de reunir renda, um deles sendo a arrecadação de tributos. Nesse sentido, é o conceito atribuído ao Direito Tributário por Vinícius Casalino (2012, p. 29): “agrupamento de normas jurídicas que regulam a relação entre o Estado e o particular, normalizando a instituição, fiscalização e a arrecadação dos tributos". 


\subsection{O DESMEMBRAMENTO DA DEFINIÇÃO LEGAL DE TRIBUTO}

Diante do conceito anterior, passa-se a entender que a relação tributária se dá entre o Estado e os particulares, estes sendo os entes que contribuem para o bem da coletividade, no sentido de que esta atinja seus objetivos, por meio do pagamento de seus tributos, porém, surge a seguinte indagação, a qual deve ser respondida para se dar continuidade ao trabalho, o que é o tributo?

Legalmente falando, ou seja, o conceito de tributo encontrado na legislação brasileira, previsto no artigo $3^{\circ}$ do Código Tributário Nacional, Lei ${ }^{\circ} 5.172$, de 25 de outubro de 1996, possui a seguinte redação: “Art. $3^{\circ}$ Tributo é toda prestação pecuniária compulsória, em moeda ou cujo valor nela se possa exprimir, que não constitua sanção de ato ilícito, instituída em lei e cobrada mediante atividade administrativa plenamente vinculada".

Ao ler o conceito de tributo, verifica-se a sua amplitude, motivo pelo qual é imprescindível que se faça uma análise detalhada segundo os ensinamentos de Caio Bartine, Sérgio Martins e Alexandre Mazza. Primeiramente, a respeito de "prestação pecuniária compulsória" e "em moeda ou cujo valor nela se possa exprimir" apontam os autores supra mencionados (MARTINS, 2013, p. 137 e 138) que aquele significa a transferência de um valor em dinheiro do contribuinte para o Estado, e que referida transferência é obrigatória, ou seja, não depende de vontade do particular, bastando, para tanto, a ocorrência do fato gerador. Já a expressão “em moda ou cujo valor nela se possa exprimir" significa dizer que o tributo pode ser pago em dinheiro ou de outra forma prevista em lei para extinguir o crédito tributário.

No que pertine a "não constituir sanção de ato ilícito" e "cobrada mediante atividade administrativa plenamente vinculada", Sérgio Martins (2016 p. 118) aponta que o tributo não é uma penalidade, como uma sanção pelo descumprimento de lei e, que a autoridade administrativa não tem liberdade de agir, ficando inteiramente vinculada a forma de exigir o tributo à previsão legal.

Por último, quanto a expressão "instituído em lei”, explica o autor Alexandre Mazza (2016, p. 90 e 91) que significa que o dever de pagar tributos sempre advém da lei, sendo sua única fonte possível, nunca surgindo de contratos, atos ilícitos, das declarações unilaterais de vontade ou de qualquer outra fonte.

\subsection{PRINCÍPIOS TRIBUTÁRIOS}

Assim, sabendo-se o que é tributo, e aproveitando-se que acabou de se explicar que o dever de pagamento advém de lei, cita-se outra disposição legislativa que impõe que a lei que atribui o dever de pagar o tributo, que é o inciso I, do artigo 150 da Constituição Federal brasileira: "Art. 150. Sem prejuízo de outras garantias asseguradas ao contribuinte, é vedado à União, aos Estados, ao Distrito Federal e aos Municípios: [...] I - exigir ou aumentar tributo sem lei que o estabeleça; [...]". 
Dessas disposições legais citadas até o momento, observa-se que a última é constitucional e a primeira é federal, ambas no mesmo sentido, qual seja, que para se ter o dever de pagar um tributo, deve-se haver uma lei que estabeleça tal obrigação, ou seja, o que se quer dizer é que ao criar uma norma sobre determinada matéria, são observadas ideias correlatas, no mesmo sentido, que fundamenta a criação das normas e devem ser respeitadas, isto é, um princípio é contemplado, e por se tratar de Direito Tributário, se atenta a um Princípio Tributário.

O Princípio Tributário nada mais é que preceitos fundamentais que devem ser observados obrigatoriamente pelo legislador e pelo Fisco, os quais descumpridos geram a nulidade do tributo ou de sua cobrança (MAZZA, 2016, p. 202), merecendo destaque os princípios da legalidade tributária e da anterioridade tributária.

É de se pensar que deixar a tributação sem um regramento não daria certo, como por exemplo se o Poder Legislativo a qualquer momento pudesse mudar a alíquota a ser paga à título de Imposto de Renda Pessoa Física, pois referida conduta geraria uma insegurança financeira e jurídica, o que é significativamente abominável pelo Direito. Diante disso, no sentido de evitar uma situação como essa, é que o Direito Tributário reconhece o Princípio da Legalidade Tributária, pois, nas palavras de Eduardo Sabbag (2010, p. 59) se o tributo é um mecanismo de apropriação patrimonial, é prudente que isso ocorra segundo a vontade popular, o que ocorre no Brasil através do Poder Legislativo, nas Câmaras dos Deputados e no Senadora Federal.

Com isso, observa-se que o Princípio da Legalidade Tributária é relacionado ao artigo 150, inciso I da Constituição Federal Brasileira, anteriormente mencionado, sendo que naquela ocasião mencionou-se que o dever de pagar um tributo advém da lei. Contudo, não é somente o dever de pagar um tributo que resulta da norma, mas a extinção de um tributo ou a minoração do valor a ser pago relativo a ele, também resultam da legislação. Sobre isso, também doutrinou Eduardo Sabbag (2010, p.59):

A constituição Federal de 1988 foi explícita ao mencionar os elementos "instituição" e "aumento", levando o intérprete, à primeira vista, a associar a lei apenas aos processos de criação e majoração do tributo. Essa não parece ser a melhor exegese: a lei tributária deve servir de parâmetro para criar e, em outro giro, para extinguir o tributo; para aumentar e, em outra bunda, reduzir a exação. Com efeito, conforme se estudará no transcorrer da obra, as desonerações tributárias, quer no plano da extinção (e.g., isenções, remissões etc.), quer no plano das reduções (v.g, redução de base de cálculo, concessão de crédito presumido etc.), adstringem-se à reserva da lei.

Com isso, percebe-se que o Princípio da Legalidade Tributária, conforme ensina Hugo de Brito Machado (2001, p. 68), é o preceito que representa que nenhum tributo pode ser criado, aumentado, reduzido ou extinto sem que o seja por lei.

Contudo, não basta que haja a criação de uma lei dispondo sobre os tributos para que se tenha uma segurança financeira e jurídica, mas também que deve existir um período de tempo a ser respeitado para que a norma tributária comece a valer, pois caso contrário, apenas 
com a criação da ordem legislativa já seria aplicável a disposição e não daria tempo das pessoas, tanto jurídica, como física, se preparem para o tipo de tributação que foi legislado. À vista disso, interessante é a existência do princípio da Anterioridade Tributária, objeto de análise a seguir.

Como explica Sergio Pinto Martins (2016, p. 103) o princípio da Anterioridade Tributária proíbe que o tributo possa ser exigido no mesmo exercício financeiro em que haja sido publicada a lei que o instituiu ou o aumentou, bem como delibera que deve ser respeitado o prazo mínimo de 90 (noventa) dias, que possui a finalidade de restringir o Estado de publicar uma lei em 31 de dezembro e já poder exigir no primeiro dia de janeiro do ano seguinte, o que prejudicaria o contribuinte por não haver tempo hábil para seu planejamento.

Aponta-se que referido princípio também tem base constitucional, no artigo 150 da Constituição Federal brasileira, inciso III, alíneas "b" e "c":

Art. 150. Sem prejuízo de outras garantias asseguradas ao contribuinte, é vedado à União, aos Estados, ao Distrito Federal e aos Municípios:

$[\ldots]$

III - cobrar tributos;

$[\ldots]$

b) no mesmo exercício financeiro em que haja sido publicada a lei que os instituiu ou aumentou;

c) antes de decorridos noventas dias da data em que haja sido publicada a lei que os instituiu ou aumentou, observado o disposto na alínea b;

$[\ldots]$

Portanto, conclui-se que há algumas proteções ao contribuinte, algumas regras tributárias que devem ser seguidas, as quais possuem o objetivo de gerar segurança à ele, além de se compreender que o Estado necessita deste contribuinte para cumprir com suas obrigações perante sua população e, que referida ajuda, se dá por meio do recolhimento de tributos.

Entendendo-se isso, no próximo capítulo haverá o estudo de um tributo em específico, sua incidência em uma atividade em particular e sobre qual ente federativo possui competência para efetuar a arrecadação.

\section{REGRAS PERTINENTES AO IMPOSTO SOBRE SERVIÇO DE QUALQUER NATUREZA E SUA RELAÇÃO COM O ENSINO SUPERIOR À DISTÂNCIA}

\subsection{O IMPOSTO COMO GÊNERO DO TRIBUTO}

Começando-se a abordar a matéria deste capítulo, destaca-se que o direito tributário brasileiro é rico em matéria de legislação, existindo além da Constituição Federal brasileira e o Código Tributário Nacional, outras diversas legislações que regulam nosso cenário contributivo, via de regra, existindo para cada espécie de tributo, uma legislação própria para tratar a matéria. 
Sobre as espécies de tributos, Sérgio Martins (2016, p. 120) inicialmente evidencia-se que o art. $5^{\circ}$ do Código Tributário Nacional prevê três tipos: os impostos, as taxas e as contribuições de melhoria. Contudo, o art. 217 do CTN, acrescentado pelo Decreto-lei $\mathrm{n}^{\mathrm{o}}$ 27, de 14-11-1996, já revelava que os tributos não são apenas os três anteriormente mencionados, pois acrescentou-se a partir desde decreto-lei uma quarta espécie, que era a contribuição social, eis que nos incisos do artigo 217 já se fazia referência a contribuição sindical, quotas de previdência, contribuição do fundo de assistência e a contribuição do FGTS.

Ademais, complementa Sérgio Martins (2016, p. 120) que analisando a Constituição, verifica-se que são cinco as espécies tributárias, o imposto, a taxa e a contribuição de melhoria mencionadas no artigo 145, as contribuições sociais legislada a partir do artigo 149 e o empréstimo compulsório vislumbrado no artigo 148, sendo que todas essas espécies estão inseridas no Capítulo I do Título VI da Constituição, capítulo este titulado como "Sistema Tributário Nacional”.

Dessas cinco espécies, estabelece-se que estudaremos mais a fundo os impostos, porém, não todos eles, mas um em específico, o Imposto Sobre Serviço de Qualquer Natureza (ISSQN), que é o tributo objeto da problemática deste estudo.

\subsection{CARACTERÍSTICA DO IMPOSTO E O FATO GERADOR}

Nesse sentido, começa-se a explicar o que é o imposto de maneira geral, pois cada espécie tributária possui suas peculiaridades. No sentido de demonstrar isso, ressalta-se o ensinamento de Vinícius Casalino (2012, p.349 e 350) que leciona que os impostos além de se adequarem ao conceito genérico do art. $3^{\circ}$ do Código Tributário Nacional, já exposto, apresentam características próprias, como por exemplo, fato gerador desvinculado de uma atividade estatal específica direcionada ao contribuinte, ou seja, deve-se recolher o imposto simplesmente porque praticou-se um fato gerador desvinculado, como é deliberado no art.16 do Código Tributário Nacional: "Imposto é o tributo cuja obrigação tem por fato gerador uma situação independente de qualquer atividade estatal específica, relativa ao contribuinte”.

Porém, para se entender o que é recolher um imposto simplesmente pelo motivo de praticar um fato gerador desvinculado de uma atividade estatal específica, deve-se ter uma noção do que é o fato gerador.

Com esse destino traçado, expõe-se que o artigo 114 do Código Tributário Nacional que descreve que o "fato gerador da obrigação principal é a situação definida em lei como necessária e suficiente à sua ocorrência", o doutrinador Rubens Gomes (1950, p. 163) conceitua fato gerador como "o fato (ou o conjunto de fatos correlatos), de cuja ocorrência a lei faz depender o nascimento do direito do Estado ao imposto" e ainda, o autor Ruy Barbosa Nogueira (1987, p. 154) ilustra que o fato gerador é "o conjunto dos pressupostos abstratos descritos na norma de direito material, de cuja concreta realização decorrem os efeitos jurídicos previstos".

Portanto, aponta-se de maneira mais simplificada que o fato gerador é uma 
situação jurídica prevista por meio de uma norma, que ao ocorrer faz surgir o direito do Ente estatal cobrar um tributo do contribuinte, no entanto, deve-se lembrar dos princípios da legalidade e da anterioridade, ou seja, é preciso perceber que para existir um fato gerador, como é para o tributo, deve haver uma lei que o defina e esse fato gerador também deve respeitar a regra de que, somente pode ser exigido no exercício financeiro posterior ao que o tributo/fato gerador foi definido, bem como o prazo mínimo de 90 (noventa) dias, como já elucidado no capítulo 2.

E ligando essa ideia com a desvinculação, expressa-se que havendo uma norma que estabelece um tributo na modalidade imposto, que haja o respeito ao princípio da legalidade e da anterioridade, e que o contribuinte pratique o fato gerador da ordem legal, surgindo para o Estado (em sentido amplo) o direito de cobrar o tributo, referido valor adquirido não ordena que o fisco tenha que empregar o montante de forma exclusiva, o que dá a ele liberdade, que pode ser considerado uma vantagem.

A respeito da ideia da desvinculação ser um benefício ao Estado, o doutrinador Vinícius Casalino (2012, p. 351), ao comentar sobre as características do imposto, falando sobre o artigo 167, inciso IV, da Constituição Federal, explica que o dispositivo proíbe a vinculação da receita de impostos a órgão, fundo ou despesa específicos, com as exceções definidas pelo próprio artigo, consistindo isso em um propósito constitucional de assegurar liberdade aos entes federativos, para que invistam as contribuições financeiras obtidas de acordo com as suas necessidade próprias de cada época.

Fechada a ideia anterior, e aproveitando que se comentou sobre os entes federativos, comenta-se que é de se pensar nesse momento, mas como saber qual tributo deve ser pago ao Município, ao Estado/Distrito Federal e à União? Essa indagação será respondida no tópico a seguir.

\subsection{DA COMPETÊNCIA TRIBUTÁRIA}

Diante da dúvida anterior que é normal surgir neste momento, elucida-se que referida temática é denominada de Competência Tributária. Essa diz respeito a atribuição advinda da Constituição Federal aos entes federativos de instituir seus impostos, o que é diverso de Competência para legislar sobre direito tributário.

Sobre essa diferença, explica Alexandre Mazza (2016, p. 60):

A competência para legislar sobre Direito Tributário é mais ampla e envolve a aptidão para disciplinar diversos temas relacionados com a tributação. Já a competência tributária restringe-se à possibilidade de instituição do tributo propriamente dita. Somente pessoas políticas detêm competência tributária.

E ainda, nessa perspectiva de entender perfeitamente o que é a Competência Tributária, importante diferenciá-la do Poder Fiscal, que segundo ensinamentos de Bernardo Ribeiro Moraes (1995, p.252 e 259), este é a permissão ilimitada advinda da Constituição Federativa do 
Brasil para estabelecer tributos sobre pessoas ou riquezas dentro do território nacional, enquanto àquela a Competência Tributária é uma parte desse poder partilhado de forma limitada a um ente federativo, podendo este ente legislar sobre a matéria a ele transferida.

Ora, pensando assim, é de se lembrar que a fonte principiológica de todo o sistema Tributário brasileiro é a grandiosa Constituição Federal, que se analisa a partir de então, já focando nos Impostos Sobre Serviços de Qualquer Natureza, objeto deste estudo e que, diante de todo o conhecimento já explanado, possível de compreendê-lo e de observar sua aplicação em uma situação específica, o que será feito mais à frente.

Por enquanto, em análise a Constituição Federal, avista-se que existem seções próprias no dispositivo constitucional dizendo a respeito dos impostos, instante que se aproveita para dizer que o objeto desse artigo diz respeito a seção $\mathrm{V}$ do art. 156 do texto constitucional, denominada de "Dos Impostos dos Municípios".

Referido artigo possui a seguinte redação focalizando-se em seu inciso III, que trata sobre serviços de qualquer natureza: "Art.156. Compete aos Municípios instituir impostos sobre: [...]; III - serviços de qualquer natureza, não compreendidos no art.155, II, definidos em lei complementar.

Como bem disciplina no dispositivo supra algarismado, o imposto sobre serviço de qualquer natureza -ISSQN, objeto do presente estudo, é de competência Municipal, diferentemente das espécies tributárias descritas no artigo 155, inciso II da Constituição Federal, que disciplinam acerca dos impostos de competência Estaduais e Distrital, como por exemplo, as operações relativas à circulação de mercadorias e sobre prestações de serviços de transporte interestadual e intermunicipal e de comunicação, ainda que as operações e as prestações se iniciem no exterior.

\subsection{DISPOSIÇÕES LEGAIS PERTINENTES AO IMPOSTO SOBRE SERVIÇO DE QUALQUER NATUREZA E A RESPEITO DA EDUCAÇÃO À DISTÂNCIA}

Voltado ao artigo 156, inciso III, acentua-se que o Vade Mecum Saraiva (2018, p.47) apresenta uma remissão abaixo do inciso imputado, que a referencio "A Lei Complementar $\mathrm{n}^{\circ}$. 116, de 31/07/2003, dispõe sobre o Imposto Sobre Serviço de Qualquer Natureza, de competência dos Municípios e do Distrito Federal".

Contemple-se, a lei complementar em questão regulamenta o tributo objeto de nosso estudo, motivo pelo qual passa-se a analisá-la.

A Lei Complementar $n^{\circ}$. 116/2003 após estabelecer sobre o que incide o ISSQN em seu artigo $1^{\circ}$ e a respeito do que não incide em seu artigo $2^{\circ}$, começa a expor sobre qual território municipal ou distrital terá competência para arrecadar o tributo, o que primeiramente ocorre no artigo $3^{\circ}$ do mesmo diploma legal. No caput deste artigo, fala-se que o serviço considerasse prestado, e o imposto devido, no local do estabelecimento prestador ou, na falta do estabelecimento, no local do domicílio do prestador, trazendo algumas exceções previstas nos incisos I a XXV do artigo em 
questão.

Sobre as exceções, verifica-se que no caso delas, ao invés de o recolhimento do imposto ocorrer no local do estabelecimento do prestador ou na falta do estabelecimento, no local de seu domicílio, o local de recolhimento será o da execução do serviço, sendo que as atividades elencadas como exceções dizem respeito a atividades relacionadas à construção civil, à varrição, à limpeza, à jardinagem, à cuidados ambientais, à guarda de bens, à serviços de diversão, à transporte coletivo municipal rodoviário, entre outros.

Todavia, observa-se que a Lei-Complementar $n^{\circ}$. 116/2003 elenca uma terceira regra sobre a competência para arrecadar o tributo chamado de Imposto Sobre Serviço de Qualquer Natureza, que se encontra no artigo $4^{\circ}$, possuidor da seguinte redação:

Art. 4 Considera-se estabelecimento prestador o local onde o contribuinte desenvolva a atividade de prestar serviços, de modo permanente ou temporário, e que configure unidade econômica ou profissional, sendo irrelevantes para caracterizá-lo as denominações de sede, filial, agência, posto de atendimento, sucursal, escritório de representação ou contato ou quaisquer outras que venham a ser utilizadas.

Ora, o artigo citado busca regrar os serviços que tanto podem ser prestados no local do estabelecimento físico da pessoa prestadora como em outras localidades, por meio da utilização da internet ou outro aparato tecnológico que permita o compartilhamento de dados, sendo exemplos desses serviços os advocatícios, contábeis, publicitários, de agenciamento e educacionais, este último, objeto de nosso estudo, sendo que o artigo em questão disciplina que o local de estabelecimento da prestação desses serviços é o local onde as atividades são desenvolvidas.

Sobre os serviços educacionais, que também é objeto de estudo deste artigo, menciona-se que a respeito deles serem passíveis da incidência tributária, consta a hipótese no anexo editado pela Lei-Complementar $n^{0}$. 116/2003, em seu item 8, oportunidade que irá se verificar a incidência do ISSQN sobre um serviço educacional específico, qual seja o Ensino à Distância (EaD), na modalidade de Ensino Superior.

Conforme conceitua a autora Maia Carmen (2007, p. 6), “A EaD é uma modalidade de educação em que os professores e alunos estão separados, planejada por instituições e que utiliza diversas tecnologias de comunicação", bem como a escritora faz menção a separação no espaço:

Em geral, a sigla EaD é aplicada a atividades de ensino e aprendizagem em que o aluno e professor estão separados fisicamente, o que as distinguem, por exemplo, do ensino presencial. Em EaD ocorre uma separação geográfica e espacial entre o aluno e o professor, e mesmo entre os próprios alunos, ou seja, eles não estão presentes no mesmo lugar, como no caso do ensino tradicional. A EaD prescinde, portanto, da presença física em um local para que ocorra educação.

Deste ensinamento, nota-se que o Ensino à Distância compreende uma Instituição, 
que pode ser pública ou privada, com o objetivo de prestar um serviço educacional, à alunos que eventualmente podem estar em municípios, estados ou até mesmo em um país diverso de onde o professor que ministra a aula se encontra, o que ocorre por conta da utilização de diversas tecnologias de comunicação, como a exemplo a gravação de educadores ensinando determinadas matérias e assuntos ou até mesmo o ensino transmitido ao-vivo, aulas que são disponibilizadas pela Instituição de Ensino, via internet, por meio de um site ou estrutura apropriada, aos educandos que aderiram ou integram ao curso que compreende as referidas vídeo aulas.

Havendo essas diversas peculiaridades pertinente ao Ensino à Distância, é de se pensar que também existem algumas legislações para regrar o tema, tais como: o Decreto $\mathrm{n}^{\circ}$. 9.235 de 2017, o Decreto $n^{\circ} .9 .057$ de 2017 e também a Portaria Normativa $n^{\circ} .11$ de 2017, que estabelecem normas para o credenciamento de instituições e a oferta de cursos superiores na modalidade à distância; regram o exercício das funções de regulamentação, supervisão e avaliação das instituições de educação superior e dos cursos superiores de graduação e de pós-graduação no sistema federal de ensino.

Diante das diversas legislações a respeito, o que merece destaque, neste momento de estudo, é o artigo 97 do Decreto $n^{\circ}$. 9.235/2017, que alterou o $\S 1^{\circ}$ do artigo $5^{\circ}$ do Decreto $n^{\circ}$. 9.057/2017, estabelecendo:

Art. $5^{\circ} \mathrm{O}$ polo de educação a distância é a unidade descentralizada da instituição de educação superior, no País ou no exterior, para o desenvolvimento de atividades presenciais relativas aos cursos ofertados na modalidade a distância.

$\S 1^{\circ}$ Os polos de educação a distância manterão infraestrutura física, tecnológica e de pessoal adequada aos projetos pedagógicos dos cursos ou de desenvolvimento da instituição de ensino.

Assim, identifica-se a existência de duas estruturas, a da instituição de educação superior e a do polo de educação à distância, surgindo, desta feira, uma indagação que merece ser respondida: sendo as duas estruturas mencionadas acima em municípios distintos, qual dos entes municipais terá Competência Tributária para arrecadar o imposto sobre a prestação do serviço educacional? O município da instituição de ensino ou a municipalidade do polo de educação à distância?

Diante da indagação, revela-se que no próximo capítulo haverá a análise e exposição de julgados de nossos Tribunais a respeito da temática.

\section{MAPEAMENTO JURISPRUDENCIAL SOBRE O LOCAL DE INCIDÊNCIA DO ISSQN MUNICIPAL E DISTRITAL}

No presente momento, caminha-se no sentido de pesquisar e expor como o Poder Judiciário vem decidindo no tocante à competência para realizar a cobrança do ISSQN, quando se envolve uma instituição de educação superior à distância prestadora, ou seja, local onde há todo o 
aparato ligado a ministração das aulas para disponibilização aos alunos que aderirem ou integram ao curso, via aparatos tecnológicos e, uma segunda estrutura, denominada de polo de educação à distância, onde o serviço é tomado, local que há uma estrutura física de apoio aos alunos aderentes, no sentido destes terem o melhor acesso possível às aulas.

Tendo isso em mente, lembrando-se que a Lei-Complementar $n^{\circ} .116 / 2003$ é a norma federal que regulamenta este assunto tendo, portanto, abrangência nacional, começa-se a análise dos julgados da corte responsável por uniformizar a interpretação da lei federal em todo território brasileiro, qual seja, a Corte do Superior Tribunal de Justiça (STJ).

Buscando-se no site do mencionado Órgão ${ }^{1}$, fazendo-se uma pesquisa jurisprudencial, com os critérios "ISSQN", "competência tributária" e "estabelecimento prestador", na data de 16/10/2018, chegou-se ao resultado da inexistência de Acórdãos Repetitivos sobre o tema, mas em contrapartida, foram encontrados 21 Acórdãos, sendo que o proferido em data mais recente, documento 01, foi o que julgou o Agravo Interno em Recurso Especial de nº 1709665/ $\mathrm{SP}^{2}$, julgado na data de 22/05/2018, pela Segunda Turma do STJ e, possuindo como relator o Ministro Mauro Campbell Marques.

No agravo interno, a recorrente sustenta que o município de São Paulo não possui legitimidade para exigir o ISS acerca de serviços realizados no Município do Rio de Janeiro, independentemente de possuir filial ou estabelecimento naquela localidade. Quanto a isso, o douto Ministro Mauro Campbell Marques, consoante entendimento jurisprudencial do STJ, firmado em sede de recurso especial representativo de controvérsia repetitiva (REsp 1.060.210/SC, Rel. Ministro NAPOLEÃO NUNES MAIA FILHO, PRIMEIRA SEÇÃO, DJe de 05/03/2013), na vigência da Lei-Complementar $n^{\circ}$. 116/03, entendeu que o município competente para exigir o imposto sobre serviço de qualquer natureza é aquele no qual se situa o estabelecimento do prestador, ou seja, a localidade em que há uma unidade econômica ou profissional capaz de realizar o serviço, de modo permanente ou temporário, negando provimento ao agravo interno.

Já o Acórdão mais antigo encontrado, documento 21 da pesquisa, é o Agravo Regimental no Agravo de Instrumento n ${ }^{0}$ 756.202-SC ${ }^{3}$, da Primeira Turma, julgado em 12/09/2006, com voto do relator Ministro José Delgado, fundamentado com base no Decreto-Lei ${ }^{\circ}$ 406, de 31 de dezembro de 1968, motivo pelo qual deixo de analisar este Acórdão.

Outrossim, o mais remoto que já considera o Decreto-Lei 116/03, documento 19 da pesquisa, é o Agravo Regimental no Agravo de Instrumento n 1272811/MG ${ }^{4}$, da Primeira Turma, julgado em 19/05/2011, por meio do relator Ministro Teori Albino Zavascki, onde o excelentíssimo Ministro ensina sobre a matéria, relatando que no caso em questão se trata de prestação de serviços de consultoria e assessoria econômica ou financeira, não se incluindo o caso

1 Disponível em < http://www.stj.jus.br/portal/site/STJ > . Acesso em: 16/10/2018.

$2 \mathrm{https}: / /$ ww2.stj.jus.br/processo/revista/documento/mediado/?componente=ATC\&sequencial=82949517\&num registro $=201702930198 \&$ data $=20180529 \&$ tipo $=91 \&$ formato $=$ PDF

$3 \mathrm{https}: / /$ ww2.stj.jus.br/processo/revista/documento/mediado/?componente=ATC\&sequencial=2469353\&num registro $=200600496940 \&$ data $=20061016 \&$ tipo $=91 \&$ formato $=\mathrm{PDF}$

$4 \mathrm{https}: / /$ ww2.stj.jus.br/processo/revista/documento/mediado/?componente=ATC\&sequencial=15284203\&num registro $=201000164045 \&$ data $=20110530 \&$ tipo $=91 \&$ formato $=$ PDF 
na exceção prevista no artigo $3^{\circ}$ da Lei-Complementar $n^{\circ}$. 116/03.

Também apontou o Ministro que a Primeira Seção do Superior Tribunal de Justiça, ao julgar o REsp 1.117.121/SP, Min. Eliana Calmon, DJe de 29/10/2009, sob o regime do artigo 543-C do CPC, reafirmou o entendimento, segundo o qual, ao fato gerador ocorrido sob a égide da Lei-Complementar nº $116 / 03$, à exceção de serviços de construção civil, o ISSQN é devido ao município do local da sede do prestador de serviço e que, este último julgado, considerando sua especial eficácia vinculativa (CPC, art.543-C, §7), impõe-se sua aplicação, nos mesmos termos, aos casos análogos, como o dos autos, negando provimento ao agravo regimental.

Todavia, com o intuito de enriquecer a pesquisa, explorar-se-á a temática por outra perspectiva, deixando-se a competência do Superior Tribunal de Justiça de lado e, adentrandose, ao Tribunal de Justiça do Paraná.

Por meio do site do citado Órgão do Estado do Paraná ${ }^{5}$, fazendo uma pesquisa detalhada, no âmbito do $2^{\circ}$ grau, selecionando-se apenas Acórdãos e, utilizando-se também dos critérios "ISSQN", “competência tributária” e "estabelecimento prestador", na data de 16/10/2018, foram encontrados 78 registros.

Destes 78 registros, o mais recente é oAcórdão den. 0006718-40.2012.8.16.0044", da $2^{\text {a }}$ Câmara Cível, com o relator Desembargador Guimarães Costa, da Comarca de Apucarana, julgado em 26/09/2018, onde no caso em comento, tratou-se de operações de leasing, e qual seria a competência tributária para cobrança do tributo, envolvendo o Município de Apucarana e o de São Paulo.

No Município de Apucarana a arrendadora utiliza de espaço em agências, porém mencionou o douto Desembargador que esse fato não ser para configurar o fato gerador do ISS, complementando que, no caso, é de conhecimento público e notório que as instituições financeiras possuem um departamento especializado na análise da situação financeira dos clientes, pretendentes a crédito, e posterior deferimento ou indeferimento do pedido de arrendamento mercantil, não sendo crível que em cada agência bancária exista um grupo de funcionários especializados encarregados de fazer a análise dos pedidos de leasing, inclusive, com buscas dos cadastros restritivos de crédito.

Fundamentou o Desembargador Relator que após a entrada em vigor da Lei Complementar 116 de 31 de julho de 2003, cumpre a aferição do local onde o serviço foi efetivamente prestado, ou seja, onde a relação é perfectibilizada, sendo que os contratos de ISS sobre leasing se sujeitam à aprovação pela direção geral da instituição financeira, a qual se efetiva na sede administrativa do ente arrendador, assim entendido o local onde se comprove haver unidade econômica ou profissional da instituição financeira com poderes decisórios suficientes à concessão e aprovação do financiamento, decisões estás de concessão dos financiamentos nos contratos de arrendamento mercantil caracterizando o fato gerador do tributo, que foram tomadas no Município de São Paulo, este Município sendo detentor da competência tributária para cobrar o tributo em

\footnotetext{
5 Disponível em: < https://portal.tjpr.jus.br/jurisprudencia/ >. Acesso em: 16/10/2018 6 Ac\%C3\%B3rd\%C3\%A3o-0006718-40.2012.8.16.0044

https://portal.tjpr.jus.br/jurisprudencia/j/4100000006966661/
} 
questão.

No sentido de ficar claro o entendimento do Tribunal de Justiça do Paraná, também se menciona a respeito do segundo julgado mais recente encontrado na pesquisa, pertinente ao processo n. 0001756-21.2017.8.16.00047, da $1^{\text {a }}$ Câmara Cível, com o relator Vicente Del Prete Misurelli, da Comarca de Curitiba Paraná, julgado em 18/09/2018, oportunidade que, a parte autora, advocacia sediada em Porto Alegre/RS, prestou serviços de advocacia para o Banco do Brasil, situado em Curitiba/PR, e, em razão disso, o tomador do serviço, em razão de decreto municipal, reteve os valores devidos a título de ISSQN, pelo fato de a empresa prestadora de serviços não ser cadastrada no Cadastro de Prestadores de Serviços de Outros Municípios (CPOM), junto à Secretaria Municipal de Finanças.

Explicou o Desembargador que a competência para cobrar tal tributo, como regra, é do município onde está situado o estabelecimento prestador, com exceção das hipóteses previstas nos incisos I a XXV do artigo $3^{\circ}$ do Decreto-Lei 116/2003, e, como os serviços prestados no presente caso se referem a advocacia, que não encontram previsão nas exceções citadas, deve ser aplicada a regra de que o ISSQN é devido pelo prestador de serviço, no Município de seu estabelecimento comercial, no caso, Porto Alegre/RS.

E apenas a título de informação, já que mencionado sobre, elucidou o excelentíssimo Desembargos Vicente Del Prete Misurreli que, por mais que seja atividade do Município de Curitiba, no tocante ao controle e pagamento de ISSQN, fiscalizar os contribuintes, com utilizando do CPOM, isso não lhe gera o direito de cobrar, do tomador do serviço, valores que a Lei Complementar Federal impõe ao prestador, como devido a outro Município.

Por fim, se faz menção ao julgado de $\mathrm{n}^{\circ}$. 76, o terceiro mais antigo encontrado pela pesquisa no site do TJPR, que haverá a analise pois os outros não tratam do decreto-lei 116/2003. Isto posto, aponta-se que o Acórdão em questão é o 693671-0, da $2^{a}$ Câmara Cível, com o relator Desembargador Cunha Ribas, da Comarca de Arapongas e julgado em 28/09/2010 , Acórdão que reconheceu à incidência do ISS sobre as operações de arrendamento mercantil e elucidou que o artigo $4^{\circ}$ do Decreto-Lei 116/2003 assegura ao Município onde ocorra a atividade de prestar serviços, o direito de lançar e cobrar o tributo, no presente caso, o imposto relativo ao serviço de financiamento.

Porém, no caso em questão, este Desembargador tinha outro entendimento sobre leasing, decidindo que no Município onde a arrendadora realiza atividade atinente à captação de clientes, é o local competente para arrecadar o tributo, pois a obtenção de clientes faz parte do serviço de arrendamento mercantil e, consequentemente, ocorre a incidência tributária no Município em evidência.

7 https://portal.tjpr.jus.br/jurisprudencia/j/4100000007246061/c\%C3\%B3rd\%C3\%A3o-0001756-21.2017.8.16.0004 8 https://portal.tjpr.jus.br/jurisprudencia/j/11021469/Ac\%C3\%B3rd\%C3\%A3o-693671-0 


\section{CONCLUSÃO}

Como consequência do estudo realizado entendeu-se que é de suma relevância que a relação tributária entre o fisco e o contribuinte seja regida por normas legislativas e princípios, no sentido de o Estado brasileiro ter patrimônio para cuidar da coletividade que abarca seu território e do contribuinte possuir segurança jurídica e financeira.

Além desse entendimento inicial, obteve-se a compreensão do que é o tributo, de que este possui espécies, uma delas sendo o imposto, que também se identificou o que é, que este possui particulares e também contém espécies.

Dentre as espécies de impostos, estudou-se sobre o ISSQN, assimilando-se que é um tributo de arrecadação a partir do Município ou do Distrito Federal, que depende da verificação de onde o serviço foi prestado ou, em alguns casos específicos, de qual tipo de serviços foi fornecido, serviços previstos na Lei-Complementar $n^{\circ}$. 116/03.

Em específico quanto ao serviço de Ensino Superior à Distância, assimilou-se a existência de duas estruturas, a da instituição de educação superior e o polo de educação à distância, a primeira prestadora do serviço, local onde há uma estrutura para esse fim, onde há uma organização, um complexo de bens imprescindíveis para o exercício da atividade educacional, como por exemplo o estúdio onde ocorre a gravação das aulas e, o polo de educação a distância, onde o serviço é tomado, local que há uma estrutura física de apoio aos alunos aderentes, no sentido dos mesmos terão o melhor acesso possível às aulas e obterem informações, mas que não possui o complexo de bens imprescindíveis para o exercício da atividade educacional em questão.

Ainda quanto ao Ensino Superior à Distância, em estudo a lei n ${ }^{\circ}$. 116/03, observando-se seu artigo $4^{\circ}$, averiguou-se que a hipótese de incidência tributária do ISSQN nos serviços educacionais prestados, ocorre no local onde as atividades são desenvolvidas, ou seja, o município competente para arrecadar o tributo é aquele onde a atividade educacional é desenvolvida, o que se entende pelo local onde fica a estrutura da instituição de educação superior.

Pertinente ao mapeamento jurisprudencial, constatou-se que o Superior Tribunal de Justiça entende desta mesma forma, sendo apontado nos julgados que o município competente para exigir o imposto sobre serviço de qualquer natureza é aquele no qual se situa o estabelecimento prestador, ou seja, a localidade em que há uma unidade econômica ou profissional capaz de realizar o serviço, de modo permanente ou temporário. E, quanto ao Tribunal de Justiça do Paraná, o mapeamento jurisprudencial indicou que este Tribunal entende que o serviço foi efetivamente prestado e é devido o recolhimento do ISSQN no local onde a relação é perfectibilizada, apontando que isso ocorre na direção geral da instituição, local onde se comprove haver unidade econômica e profissional com poderes decisórios suficientes à prestação do serviço, que geram o fato gerador do tributo, bem como que quem deve recolher o ISSQN é o prestador do serviço e que o artigo $4^{\circ}$ do Decreto-Lei 116/2003 assegura ao município onde ocorra a atividade de prestar serviços, o direito de lançar e cobrar o tributo. 
Sendo assim, por fim, percebeu-se que ambos os tribunais entendem que, com base na lei $n^{\circ} .116 / 2003$, existindo duas estruturas, uma prestadora e uma tomadora, o Município competente para exigir o ISSQN é aquele no qual se situa o estabelecimento prestador capaz de realizar o serviço, onde a relação é perfectibilizada, onde se tem a unidade econômica e profissional com poderes de decisórios suficientes a prestação do serviço, ou seja, no local da instituição de ensino superior.

\section{REFERÊNCIAS}

BERTINE, Caio. Direito Tributário. São Paulo: Revista dos Tribunais, 2013.

BRASIL, Constituição da República Federativa do Brasil. São Paulo: Revista dos Tribunais, 2014.

. DECRETO No 9.235. Dispõe sobre o exercício das funções de regulação, supervisão e avaliação das instituições de educação superior e dos cursos superiores de graduação e de pósgraduação no sistema federal de ensino. Decretado pela Presidência da República. Diário Oficial da União, Brasília em 15 de dezembro de 2017.

. LEI COMPLEMENTAR No 116. Dispõe sobre o Imposto Sobre Serviços de Qualquer Natureza, de competência dos Municípios e do Distrito Federal, e dá outras providências. Decretada pelo Congresso Nacional e sancionada pela Presidência da República. Diário Oficial da União, Brasília em 31 de julho de 2003.

. LEI No 5.172. Código Tributário Nacional. Decretado pelo Congresso Nacional e sancionado pela Presidência da República. Diário Oficial da União, Brasília em 25 de outubro de 1966.

CARMEN, Maia. ABC da EaD. São Paulo: Pearson Prentice Hall, 2007.

CASALINO, Vinícius. Teoria geral e direito constituição tributário; Curso de direito tributário e processo tributário. São Paulo: Revista dos Tribunais, 2012.

CÉSPEDES, Lívia; ROCHA, Fabiana Dias da. Vade Mecum Saraiva: OAB. São Paulo: Saraiva, 2018.

MACHADO, Hugo de Brito. Curso de Direito Tributário. São Paulo: Malheiros, 2001.

MARTINS, Sergio Pinto. Manual de direito tributário. São Paulo: Saraiva, 2016.

MAZZA, Alexandre. Manual de direito tributário. São Paulo: Saraiva, 2016.

MORAES, Bernardo Ribeiro de. Compêndio de Direito Tributário. Rio de Janeiro: Forense, 1995.

NOGUEIRA, Ruy Barbosa. Curso de direito tributário. São Paulo: Saraiva, 1987. 
SABBAG, Eduardo. Manual de direito tributário. São Paulo: Saraiva, 2010.

SOUSA, Rubens Gomes de. Estudos de direito tributário. São Paulo: Saraiva, 1950.

Recebido em: 23/04/2019.

Aprovado em: 29/04/2019. 